\title{
Single well seismic imaging of a gas-filled hydrofracture
}

\author{
Thomas M. Daley, Roland Gritto, Ernest L. Majer \\ Lawrence Berkeley National Laboratory, 1 Cyclotron Rd. MS 90-1116, Berkeley, \\ $C A, 94720$
}

(November 4, 2003)

\begin{abstract}
A single well seismic survey was conducted at the Lost Hills, Ca oil field in a monitoring well as part of a CO2 injection test. The source was a piezoelectric seismic source and the sensors were a string of hydrophones hanging below the source. The survey was processed using standard CMP reflection seismology techniques. A potential reflection event was observed and interpreted as being caused by a near vertical hydrofracture. The radial distance between the survey well and the hydrofracture is estimated from Kirchoff migration using a velocity model derived from cross well seismic tomography. The hydrofracture location imaged after migration agrees with the location of an existing hydrofracture.
\end{abstract}

\section{INTRODUCTION}

Since the beginning of seismic exploration in the 1930's, borehole seismic measurements have been used to augment surface seismic methods (e.g. check-shot velocity surveys) or well-logging methods (e.g. sonic logging). These borehole techniques were developed into current technologies such as 3D Vertical Seismic Profiles (VSP) for structural imaging and dual dipole sonic logging for measuring anisotropic rock properties. Crosswell seismic methods have also been developed to improve subsurface properties measurement and structural imaging over interwell distances (typically 
less than $1000 \mathrm{~m}$ ). The fundamental issues driving this technology development are the ability to improve resolution (via increased frequency content) by placing seismic sources and/or sensors in the subsurface, below the highly attenuating near-surface material, and the ability to measure seismic properties in a zone of interest without adding uncertainty from propagation through other zones. These same issues continue to drive recent research in developing and applying methods of extending the penetration of conventional seismic logging from a few meters out to tens if not hundreds of meters. This logical extension of sonic logging, using techniques developed in VSP and crosswell seismic acquisition, including borehole seismic sensor strings and sources capable of exciting frequencies from 10s to 1000s of $\mathrm{Hz}$, both on a single cable, is termed single well seismic imaging (SWSI). As exploration and production wells increase in both cost and accuracy of positioning, methods to image in the vicinity of a single well and guide drilling become more necessary. Development of single well acquisition systems has been anticipated by attempts to numerically model single well data (Kurkjian, et al., 1994).

Initial success at single well imaging of a gas-filled fracture zone in a shallow ground-water test site (Majer, et al., 1997), led to development of a larger scale system for deeper wells (Daley, 1997; Daley, 1998). Our SWSI acquisition development work has progressed through these various field tests to a current system capable of CMP type borehole surveys with multiple borehole source and receiver options on a 10,000 ft cable. Recent field experiments have been aimed at targets which present a strong velocity contrast with near vertical orientation such as the flank of a salt dome or a gas filled hydrofracture. The results from a gas-filled $\left(\mathrm{CO}_{2}\right)$ hydrofracture imaging experiment are presented in the following. 


\section{DATA ACQUISITION}

\section{Field Site - Lost Hills, California}

The field site was developed as a subsurface $\mathrm{CO}_{2}$ injection pilot program operated by Chevron USA Production Company in the Lost Hills, California oil field. This pilot program, which was partially funded by the U.S. Department of Energy (DOE) as an enhanced oil recovery project, provided a site with dedicated observation wells near a hydrofracture (Figure 1). Figure 1 shows two hydrofracs near the single well survey, an initial water injection in well 11-8W, and the $\mathrm{CO}_{2}$ injection in 11-8WR (a redrilled section of 11-8W). The hydrofrac direction is estimated from previous well tests, local faulting, and tilt meter measurements (Perri, et al, 2000). The well 11-8WR was drilled, cased, perforated (in the interval from 1627 to $2105 \mathrm{ft}$ ) and hydrofracured using standard methods. The observation well OB-C1 is located about $18 \mathrm{~m}(60 \mathrm{ft})$ from the current injection well and about $12 \mathrm{~m}(40 \mathrm{ft})$ from the previous hydrofrac and water injection well (at reservoir depths and allowing for well deviations).

The reservoir rock in the Lost Hills field is a form of diatomite. The composition of the diatomite at Lost Hills is varying parts biogenic silica, clay and silt/sand (Graham and Williams, 1985). The reservoir extends from about $425 \mathrm{~m}$ (1400 ft) to $640 \mathrm{~m}$ (2100 ft) below ground level, with some variation in diatomite composition, over this interval. Porosity is $50-60 \%$ and permeability is $1-3 \mathrm{mDa}$ (Fossum and Fredrich, 2000).

The injection of $\mathrm{CO}_{2}$ began in August of 2000 and continued with varying injection pressures up to the time the single well survey was performed. The wellhead pressure was held at 800-900 psi, and the reservoir temperature was about $108{ }^{\circ} \mathrm{F}$. At this pressure and temperature, the $\mathrm{CO}_{2}$ would be in gas phase in the reservoir. The site had a water flood operating previously, so the reservoir fluids are a mix of water, oil 
and gas.

\section{Single well seismic equipment}

The single well system developed by LBNL uses modified equipment originally built for crosswell or VSP acquisition, along with a wireline cable and tube-wave suppressor (TWS) specifically designed for single well seismic acquisition. Modularization allows sources and sensors to changed independently. The configuration used to acquire the data presented here consisted of a piezoelectric seismic source, a borehole digitizer, a tube-wave suppressor, and a string of 24 borehole hydrophones (at $10 \mathrm{ft}$ interval spacing). The minimum source-receiver offset (to the top sensor) was $90 \mathrm{ft}$. The special design piezoelectric source has a frequency range of approximately 500 to $5000 \mathrm{~Hz}$. The TWS was developed by Idaho National Engineering Laboratory and uses a gas filled bladder kept slightly below borehole pressure to attenuate tube-waves. The borehole digitizer, which has 24 data channels and uses fiber-optic communication, and the hydrophone string were built by Geospace Engineering. A special design wireline (1.1 inch diameter, 10,000 ft length) with fiber-optic (FO) cables for data transmission is used with specially designed FO connections to deploy the system components in the borehole. A schematic representation of the acquisition equipment as deployed is shown in Figure 2.

\section{OB-C1 Acquisition}

The survey was designed to allow borehole CMP imaging. Borehole CMP imaging is accomplished by increasing the distance between the source and the receiver in the well from a few meters to over a hundred meters, depending upon the desired distance of investigation. Optimal data acquisition would allow the source-sensor spacing to be variable depending on the target distance. As with surface seismic acquisition, a 
good acquisition geometry would have source-receiver offsets both less and greater than the target distance.

Unfortunately, our system could not be optimally configured for the Lost Hills site because of modification costs and time constraints. The hydrofracture was expected at 30 to $60 \mathrm{ft}$ distance and our minimum offset was $90 \mathrm{ft}$. Also, the receiver spacing of $10 \mathrm{ft}$ was not optimal because the dominant wavelength of the data was about $4 \mathrm{ft}$ (1500 Hz frequency for $5500 \mathrm{ft} / \mathrm{s}$ velocity) so waves traveling along the borehole were spatially aliased. The spatial aliasing limited use of some analysis tools such as F-K filtering in shot gathers. Also, the longer offset sensors (from about 200 to $320 \mathrm{ft}$ ) had no contribution to the CMP stack at the arrival time of the hydrofrac reflection. Nonetheless, the data acquisition produced high signal-to-noise with significant (20 to $30 \mathrm{~dB}$ ) tube-wave reduction (Daley, et al., 2003). The data acquisition parameters for the OB-C1 survey are given in Table 1. An example shot gather is shown in Figure 3. In this shot gather the direct $\mathrm{P}$-wave arrival is identified along with the event which is interpreted as a reflection from the hydrofracture. A small (i $1 \mathrm{~ms}$ ) variation in delay time between the direct $\mathrm{P}$-wave and the reflection event is seen in Figure 4 in which the direct $\mathrm{P}$-wave is shifted to be aligned at $10 \mathrm{~ms}$. This variable delay time indicates the event is not a multiple. Discriminating between multiples and reflections is difficult because of the long source-receiver offset, and is discussed later.

Acquisition time is usually an important issue in borehole recording because of costs and well stability. The use of fluid coupled source and sensors decreased acquisition time to less than one minute per shot point using a stop-to-shoot method. Shooting while moving, as is done in sonic logging and some crosswell surveys, is possible and would further decrease acquisition time. 


\section{TABLES}

Table 1: OB-C1 SWSI Acquisition Parameters

Source Type: Piezoelectric with $0.5 \mathrm{~ms}$ Pulse ( $500-4000 \mathrm{~Hz})$

Sensor Type: Hydrophone

Survey Shot Depths: 1100-1800 ft

Shot Spacing: $2 \mathrm{ft}$

Sensor Spacing: $10 \mathrm{ft}$

Minimum Offset: $90 \mathrm{ft}$

Maximum Offset: $240 \mathrm{ft}$

Sample Rate: $0.125 \mathrm{~ms}$

Record Length: $250 \mathrm{~ms}$ 


\section{DATA ANALYSIS}

\section{Processing}

The data processing followed the flow chart shown in Figure 5. Initial signal enhancement, such as bandpass filtering and predictive deconvolution (used to reduce short path multiples) was done with common offset gathers (equivalent to common receiver) because the spatial aliasing apparent in shot gathers was not problematic in offset gathers. It is notable that a SWSI common offset gather is equivalent to a very long spaced, full-waveform sonic log, albeit with different frequency content. An example common offset gather is shown in Figure 6 which also demonstrates the effect of the predictive deconvolution. The same gather is shown after normalizing the amplitudes and aligning the first arrival in Figure 7. The time difference between the direct arrival and the interpreted reflection is shown in Figure 8. The $0.3 \mathrm{~ms}$ variation in time difference is about $9 \%$ of the total. This variation indicates the reflection event is not a simple multiple which would have constant time difference.

A first break mute was used to prevent the first arrival being stacked in the CMP gather. A source static of $2.5 \mathrm{~ms}$ was applied because of the difference between recording zero time and the beginning of the source pulse (as measured by an accelerometer mounted on the source).

The velocity analysis is the processing step potentially most different from surface seismic because, for a vertical borehole, typical velocity layering is perpendicular to the acquisition line, rather than parallel. In our data the velocity analysis was limited by the lack of short offsets, and poor resolution of the hydrofrac reflection on the far offsets because of NMO stretch. After binning CMP's 3-to-1, giving a $3 \mathrm{ft}$ bin size with maximum fold of 24 , and applying a stretch mute, there were typically only 6-9 traces with non-zero amplitude stacking at the hydrofracture reflection arrival time. We approached this problem by making a simplifying assumption. We assumed the 
diatomite unit could be treated as having constant stacking velocity. This assumption was validated (within 10\%) by first arrival picking and by semblance analysis of the hydrofracture event. The stacking velocity used, $5500 \mathrm{ft} / \mathrm{s}$, was in agreement with the velocity measured by first arrivals and semblance analysis. The result of a typical semblance velocity analysis is shown in Figure 9. We interpret the high semblance energy apparent at low velocity ( below $4500 \mathrm{ft} / \mathrm{s}$ ) in Figure 9 as being associated with tube-waves propagating up and down the borehole. We did not attempt to remove borehole tube-waves beyond bandpass filtering and the in-field attenuation gained by the TWS. This was acceptable because our reflection of interest (the hydrofracture plane) was expected to arrive before the tube-wave. After choosing the stacking velocity, the data was corrected for NMO. A typical CMP gather after NMO correction using the $5500 \mathrm{ft} / \mathrm{s}$ stacking velocity is shown in Figure 10 The complete single-well CMP time section is shown in Figure 11.

The final processing step was a Kirchoff depth migration, using a 2D velocity model. This velocity model was taken from crosswell tomography between OB-C1 and OB-C2 with well spacing of about $25 \mathrm{~m} /$ citeGritto03. The migrated single well result is analogous to a surface seismic depth section. For single well imaging, the analogue of a depth section is a "radial" section in which two-way reflection time is converted to the radial distance from the borehole. In this domain, any reflecting object or interface at equal radial distance for a given borehole depth will be superimposed. The result of the depth migration is shown in Figure 12.

\section{Interpretation}

The high amplitude reflection between 12 and $14 \mathrm{~m}$ distance in Figure 12 is interpreted as the hydrofracture. Because the azimuth of this reflection is unknown, the interpretation is based on a "most likely cause" reasoning. Two hydrofracs are located within 10 to $20 \mathrm{~m}$ of the survey well, a water-flood hydrofrac from well 11-8W 
and the $\mathrm{CO}_{2}$ injection hydrofrac in the redrilled 11-8WR (shown in Figure 1). We assume that the reflection is in the plane containing the survey well and normal to the hydrofrac. At 12-14 m distance, the reflection event is most likely associated with the original water-flood hydrofrac, rather than the current $\mathrm{CO}_{2}$ injection hydrofrac. Our interpretation is that the two hydrofracs are connected by high permeability sub-parallel fracturing and that the gas phase $\mathrm{CO}_{2}$ has displaced water in both hydrofracs. Communication with field production personnel has confirmed that this type of "interference" between the hydrofracs is possible. The previous water floods (which were ongoing for years) could have created high permeability pathways for the gas phase $\mathrm{CO}_{2}$.

A second reflection event at about $18 \mathrm{~m}$ distance is interpreted as the $11-8 \mathrm{WR}$ hydrofrac. The strong reflection from the closer hydrofrac will limit the energy available for reflection from the main $\mathrm{CO}_{2}$ hydrofrac in 11-8WR since energy must be transmitted twice through the closer 11-8W hydrofrac.

The 11-8W hydrofrac reflection is easily seen in a common offset gather in Figure 6 at about $29 \mathrm{~ms}$ with reversed polarity from the direct arrival (at about $25 \mathrm{~ms}$ ). The polarity reversal is consistent with a low-velocity reflector such as a gas-filled fracture zone. Accurate modeling of reflection from a hydrofracture would be best accomplished using the method of (Coates and Schoenberg, 1995) which would allow the hydrofracture to be a displacement discontinuity. Such a discontinuity should have a P-to-S conversion. We calculated the travel time for P-to-S conversion from a vertical interface at $12 \mathrm{~m}$ distance in a homogeneous media with $\mathrm{P}$ velocity of 1675 $\mathrm{m} / \mathrm{s}$ and $\mathrm{S}$ velocity of $800 \mathrm{~m} / \mathrm{s}$. This travel time for a $36.6 \mathrm{~m}$ offset $(120 \mathrm{ft}$ ) has a 11.4 ms delay after the P-to-P reflection. On Figure 6 this P-to-S event would arrive at about $40 \mathrm{~ms}$ where there is some energy arriving, although it is dominated by low frequencies which are probably tube-waves (expected to arrive at about $37 \mathrm{~ms}$ ).

If the event interpreted as a reflection from the $11-8 \mathrm{~W}$ hydrofrac is not a reflection from a vertical interface parallel to the borehole, a remaining possibility is that it is 
a multiple reflection from the equipment string. The lack of small receiver offsets in the CMP gathers prevents discrimination based on move-out analysis. However, the possibility of an equipment multiple is discounted because the following observations. First, there is a variation in amplitude as a function of depth seen in the migrated section in Figure 12. An equipment multiple should not vary in amplitude as the equipment moves. Furthermore, the event shows some variation in delay time as a function of depth as shown in Figure 8. Also, the $4 \mathrm{~ms}$ delay time after the direct arrival (shown in Figure 6) corresponds to about a $6 \mathrm{ft}$ distance for a tube-wave peg-leg multiple or a $7.3 \mathrm{ft}$ distance for a p-wave multiple, and nothing in the equipment string has this separation from the source. Therefor, the event is not easily attributable to a simple multiple, and the best interpretation is a reflection.

The reflection is strongest between 1500 and $1750 \mathrm{ft}$, with a shallower high amplitude zone between 1250 and $1350 \mathrm{ft}$. The field operators reported that hydrofrac injection pressures were allowed to rise above lithostatic pressure. We therefor believe that the 1250 to $1350 \mathrm{ft}$ interval represents an accumulation of gas, which has likely been able to migrate upward when the hydrofrac propagated above the injection interval. A later event seen at about $15 \mathrm{~m}$ radial distance in Figure 12 is possibly due to the second hydrofracture (in well 11-8WR) shown in Figure 1 at about $15 \mathrm{~m}$ distance from the bottom of well OB-C1.

\section{CONCLUSIONS}

We have successfully applied the recently developed SWSI technique to reflection imaging of gas-filled fracture zones in an oil field. The radial distance to the fracture zone was determined, as a function of depth. Variations in the fracture zone reflectivity as a function of depth were observed.

Specific equipment geometry (ie the minimum source-receiver distance) limited the CMP imaging method. Allowing for improvements in acquisition equipment, 
we believe that improved imaging, including imaging of fluid-filled fracture zones, is possible. Single-well imaging could also be a powerful method if used in a time-lapse sense where borehole effects do not vary.

Borehole CMP imaging is accomplished by varying the distance between the source and the receiver in the well. However, as one increases the source-receiver distance many problems become more severe. In effect, one now is trying to image in a true 3-D sense away from the well, therefore, directionality becomes important for the transmitted as well as the received signals. This technique needs multicomponent sources and receivers with independent azimuthal measurement to address true 3D issues. Although this can be an advantage, such issues as radiation patterns, source generated noise, borehole interaction, tube waves and other sources of noise become more problematic.

Recent and near future advances in instrumentation will make the method more economical and possibly deployable through the end of tubing. Current applications include hydrofracture monitoring, steam/water flood monitoring, fracture mapping and validation of drilling paths in horizontal drilling applications.

\section{REFERENCES}

Coates, R. T. and Schoenberg, M., 1995, Finite-difference modeling of faults and fractures: Geophysics, Soc. of Expl. Geophys., 60, 1514-1526.

Daley, T.M., Gritto, R., Majer, E.L. and West, P., Tube-wave suppression in singlewell seismic acquisition, Geophysics, 68, 863-869.

Daley, T.M. and Cox, D., 2001, Orbital vibrator seismic source for simultaneous Pand S-wave crosswell acquisition, Geophysics, 66, 1471-1480.

Daley, T.M., 1998, Single Well Seismic Imaging Tests: Nov 1997 at Bayou Choctaw Site, LBNL Report \#42672, Berkeley, Ca. 
Daley, T.M., 1997, Single Well Seismic Imaging in a Deep Borehole using a piezoelectric Orbital Vibrator, LBNL Report \#42673, Berkeley, Ca.

Fossum, A.F., and Fredrich, J.T., 2000, Constitutive models for the Etchegoin sands, Belridge diatomite, and overburden formations at the Lost Hills Oil Field, California, Sandia National Laboratory Report, SAND2000-0827.

Graham, S.A. and Williams, L.A., 1985, Tectonic, depositional, and diagenetic history of Monterey formation (Miocene), central San Joaquin basin, California, AAPG Bulletin, 69, p385-411.

Gritto, R., Daley, T. M., Myer, L. R., Joint Cross Well and Single Well Studies at Lost Hills, California, submitted to Geophysical Exploration, Lawrence Berkeley National Laboratory Report, LBNL-50651, Berkeley, CA, 2002.

Kurkjian, A.L., Coates, R.T., White, J.E., and Schmidt, H., 1994, Finite-difference and frequency-wavenumber modeling of seismic monopole sources and receivers in fluid-filled boreholes, Geophysics, 59, p1053-1064.

Majer, E.L., Peterson, J.E., Daley, T.M., Kaelin, B., Queen, J., D’Onfro, P., and Rizer. W, 1997, Fracture Detection using Crosswell and Single Well Surveys, Geophysics, 62, 495-504.

Perri, P.A., Emanuele, M.A., Fong, W.S., and Morea, M.F., 2000, Lost Hills $\mathrm{CO}_{2}$ pilot: evaluation, design, injectivity test results and implementation, Proceedings SPE/AAPG Western Regional Meeting, SPE 62526, pp 13.

\section{ACKNOWLEDGMENTS}

This work was supported by the Assistant Secretary for Fossil Energy, National Petroleum Office of the U.S. Department of Energy under Contract No. DE-AC03- 
76SF00098. Thanks to Mike Morea of Chevron and to the LBNL field personnel, especially Cecil Hoffpauir and Don Lippert. 


\section{FIGURES}

FIG. 1. Well locations and estimated hydrofrac locations for the Lost Hills $\mathrm{CO}_{2}$ injection site. Well OB-C1 was used for single-well imaging. Note that both observation wells are deviated and the top and bottom locations are marked separately (circle and $\mathrm{X}$, respectively) with dots showing intermediate locations. The section of well used for data acquisition was nearly vertical and aligned with the bottom hole location of OB-C1.

FIG. 2. Schematic of LBNL's single well acquisition equipment.

FIG. 3. Single well shot gather for a source at $1600 \mathrm{ft}$ and sensors from 1690 to $1920 \mathrm{ft}$. The data has been bandpass filtered from 1200 to $3500 \mathrm{~Hz}$.

FIG. 4. Shot gather from Figure ?? after time shifting to align the direct P-wave at $10 \mathrm{~ms}$. Each trace is normalized to its own maximum amplitude (not true relative amplitude).

FIG. 5. Flow chart for processing sequence of the single well CMP data.

FIG. 6. Comparison of common offset gather (offset $=120 \mathrm{ft}$ ) before (left) and after (right) predictive deconvolution for source depths 1600 to $1700 \mathrm{ft}$. The deconvolution had an operator length of $1.5 \mathrm{~ms}$ and a prediction length of $0.75 \mathrm{~ms}$ with $0.1 \%$ noise added.

FIG. 7. Same data as Figure ?? with amplitudes normalized to individual trace maximum and time shifted to align the direct arrival at $25 \mathrm{~ms}$.

FIG. 8. Travel time difference between the direct P-wave arrival and the interpreted 
reflection event for the data in Figure ??.

FIG. 9. Velocity semblance for cmp \#645. Higher semblance is red (meaning larger amplitude within a time window after stacking). The small red bullseye at 12-14 $\mathrm{ms}$ and $5500 \mathrm{ft} / \mathrm{s}$ represents the energy associated with the interpreted hydrofracture reflection. The low velocity, high semblance energy is interpreted as borehole tube waves.

FIG. 10. NMO corrected CMP gather. Data are plotted at true relative amplitude after applying spherical divergence correction.

FIG. 11. Single well stacked CMP time section.

FIG. 12. Migrated single well CMP section. Distance in this section is radial (essentially horizontal) from the borehole, while depth is vertical along the borehole. 


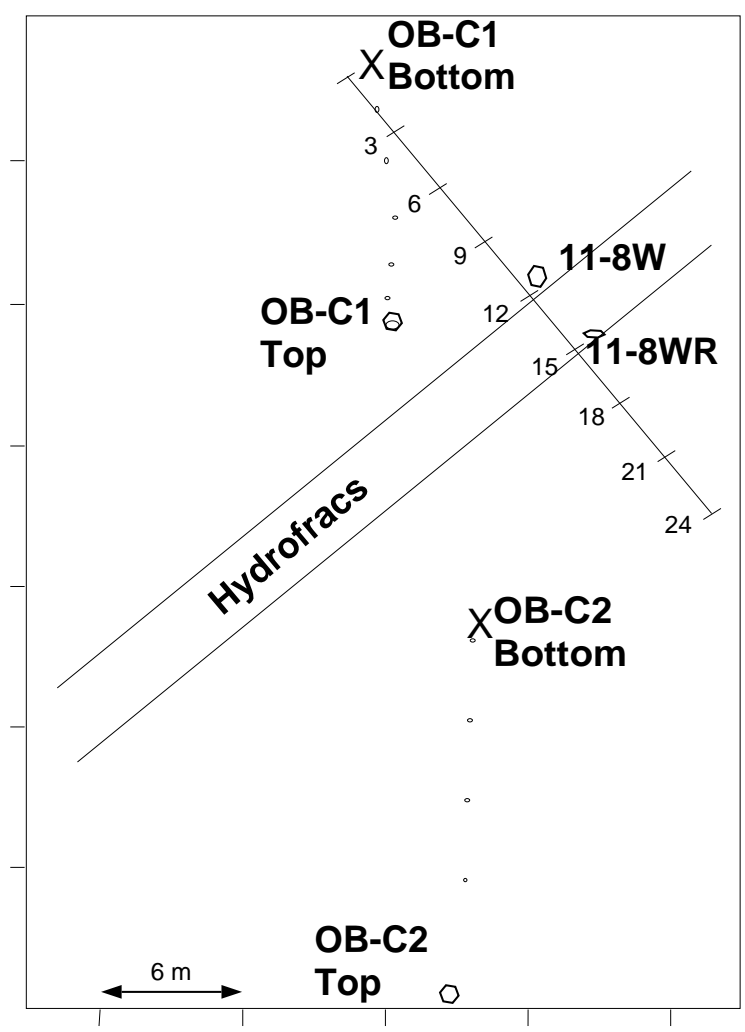

FIG. 1. Well locations and estimated hydrofrac locations for the Lost Hills $\mathrm{CO}_{2}$ injection site. Well OB-C1 was used for single-well imaging. Note that both observation wells are deviated and the top and bottom locations are marked separately (circle and X, respectively) with dots showing intermediate locations. The section of well used for data acquisition was nearly vertical and aligned with the bottom hole location of OB-C1. 


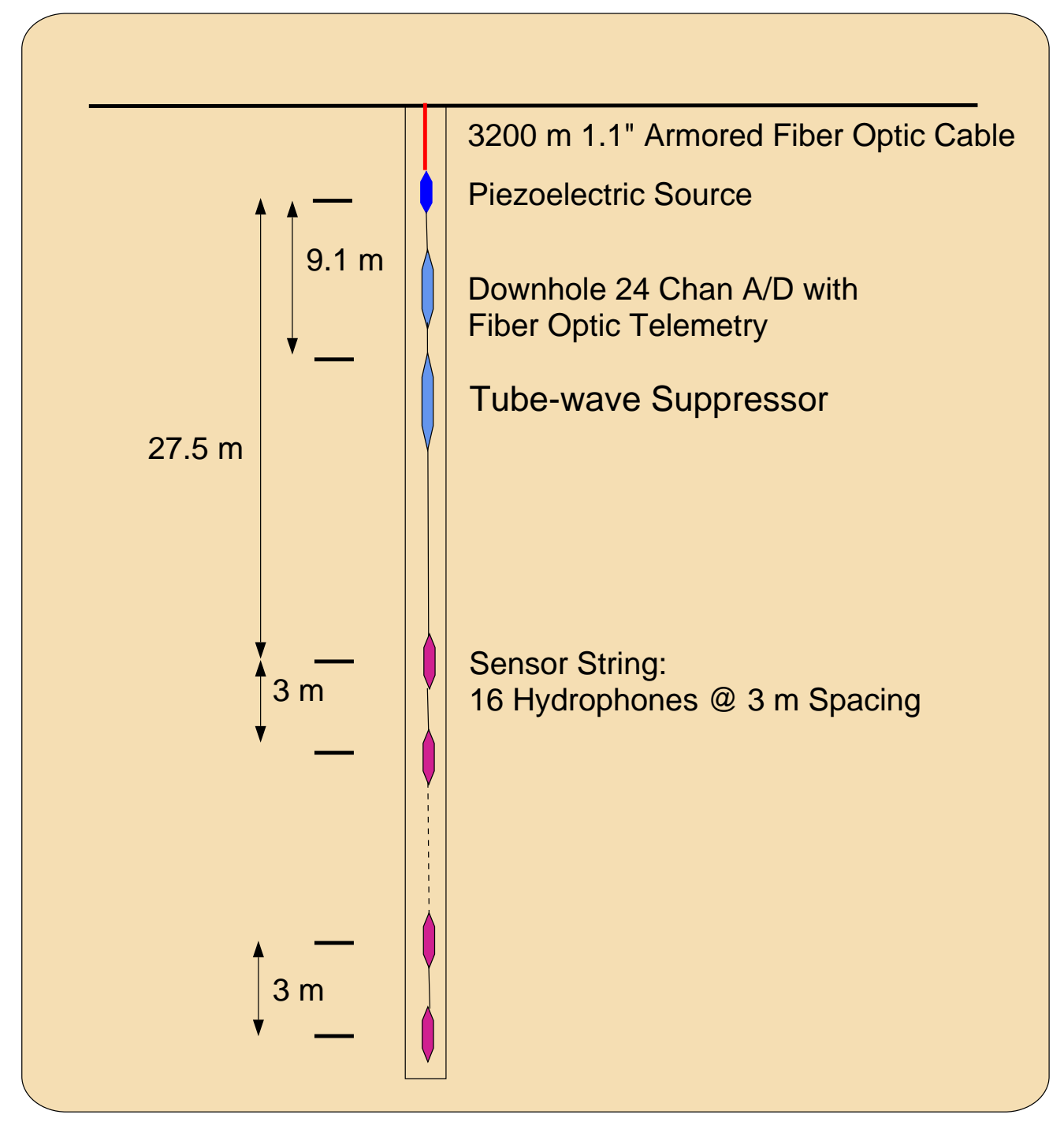

FIG. 2. Schematic of LBNL's single well acquisition equipment. 


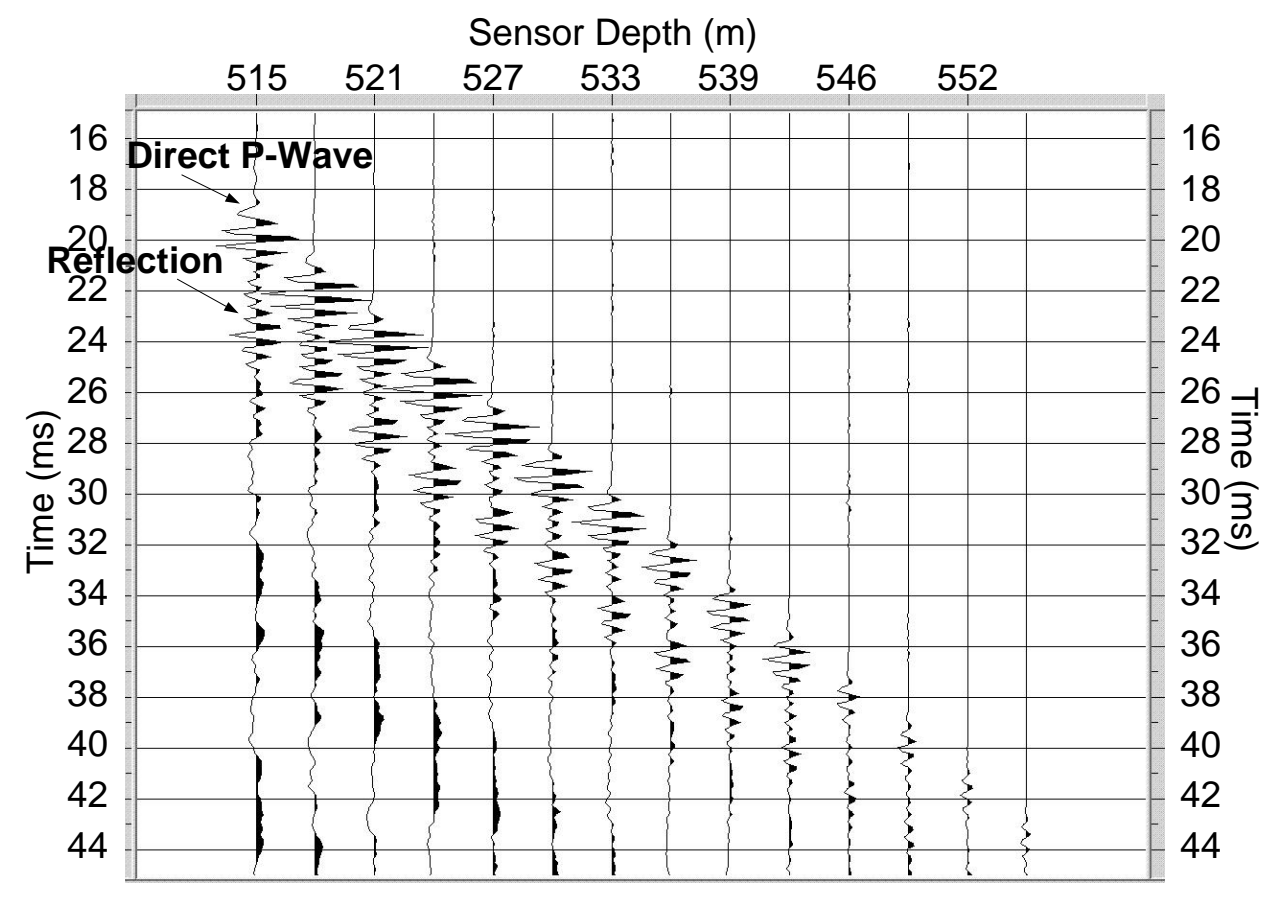

FIG. 3. Single well shot gather for a source at $1600 \mathrm{ft}$ and sensors from 1690 to $1920 \mathrm{ft}$. The data has been bandpass filtered from 1200 to $3500 \mathrm{~Hz}$. 


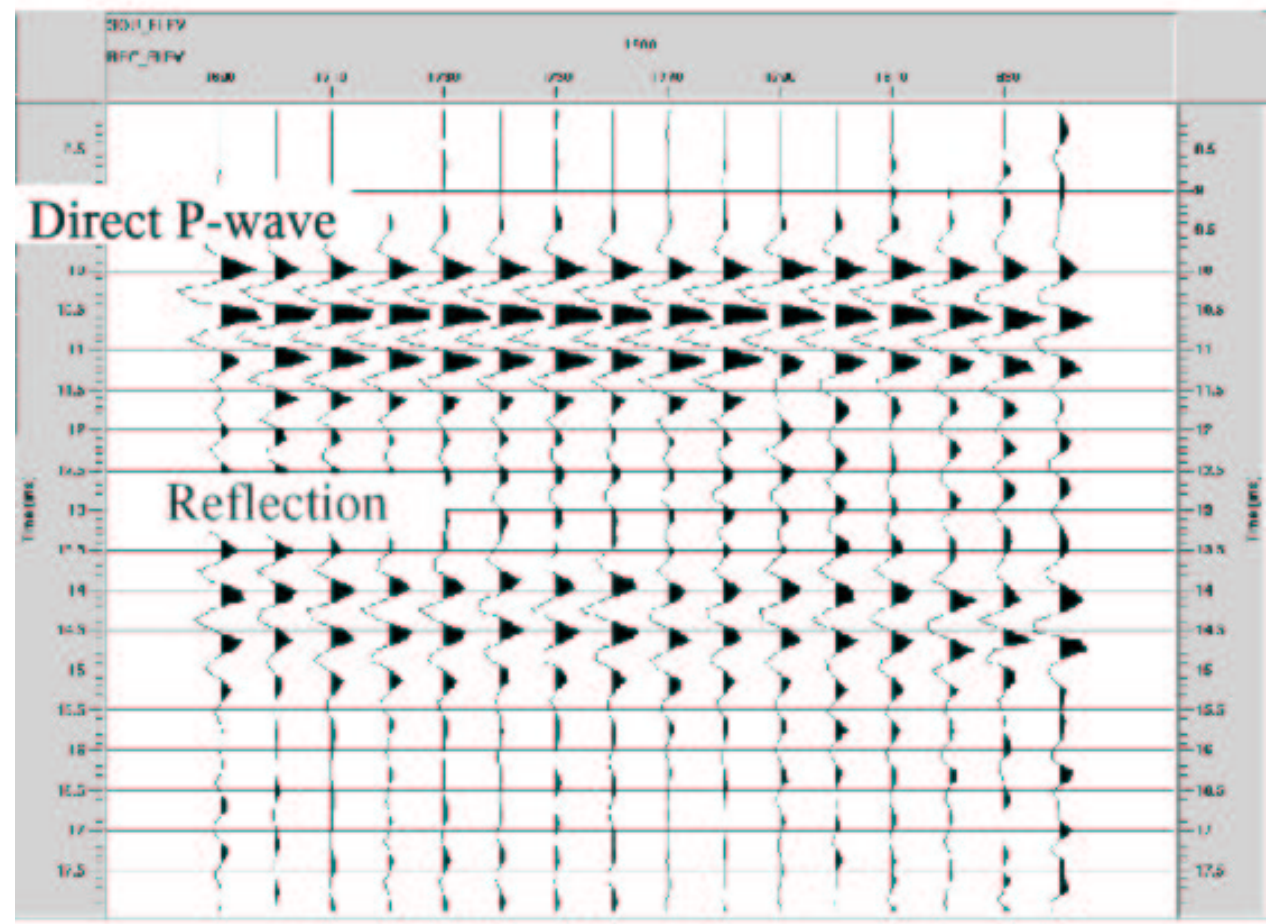

FIG. 4. Shot gather from Figure 3 after time shifting to align the direct $\mathrm{P}$-wave at 10 ms. Each trace is normalized to its own maximum amplitude (not true relative amplitude). 


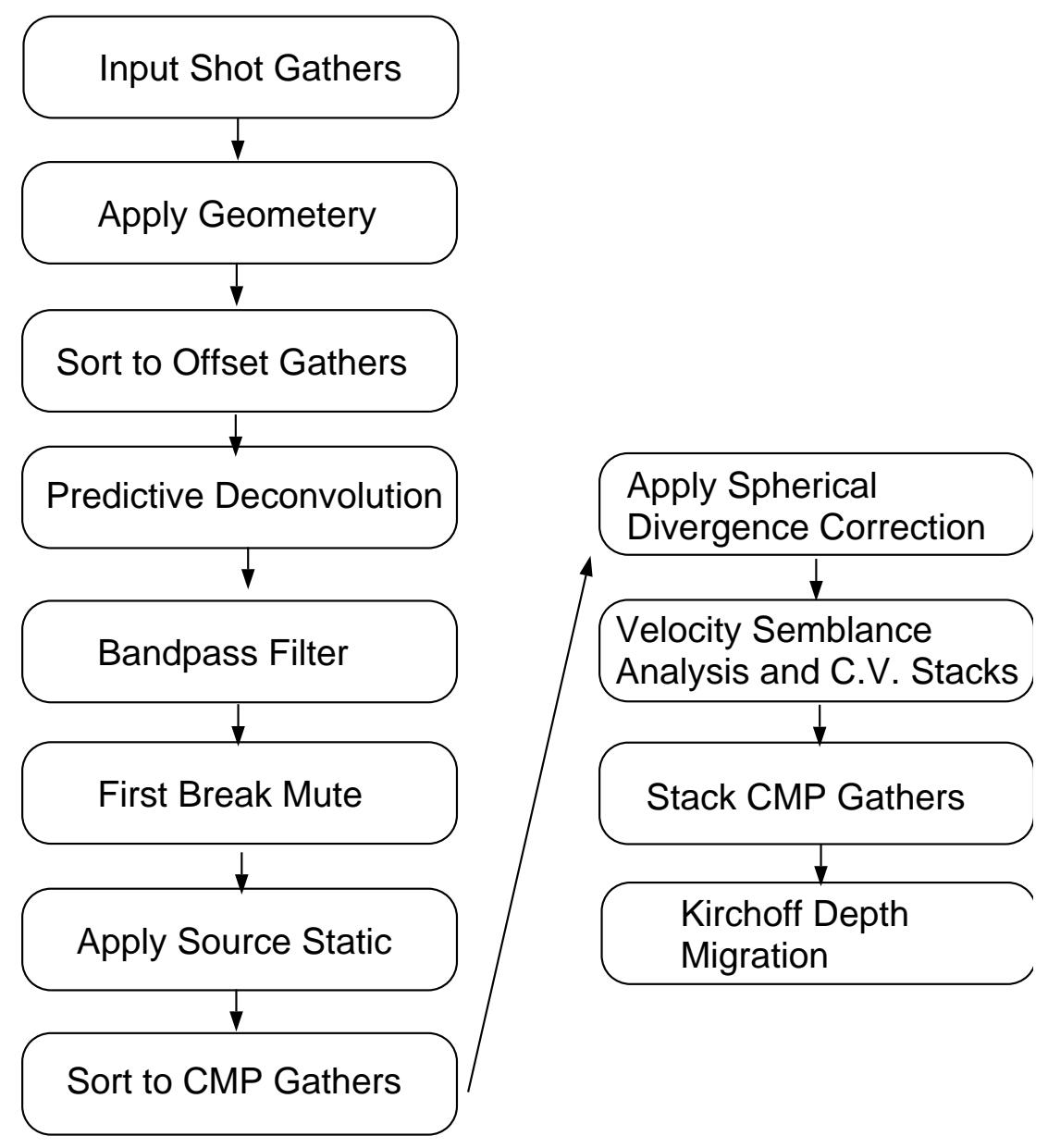

FIG. 5. Flow chart for processing sequence of the single well CMP data. 


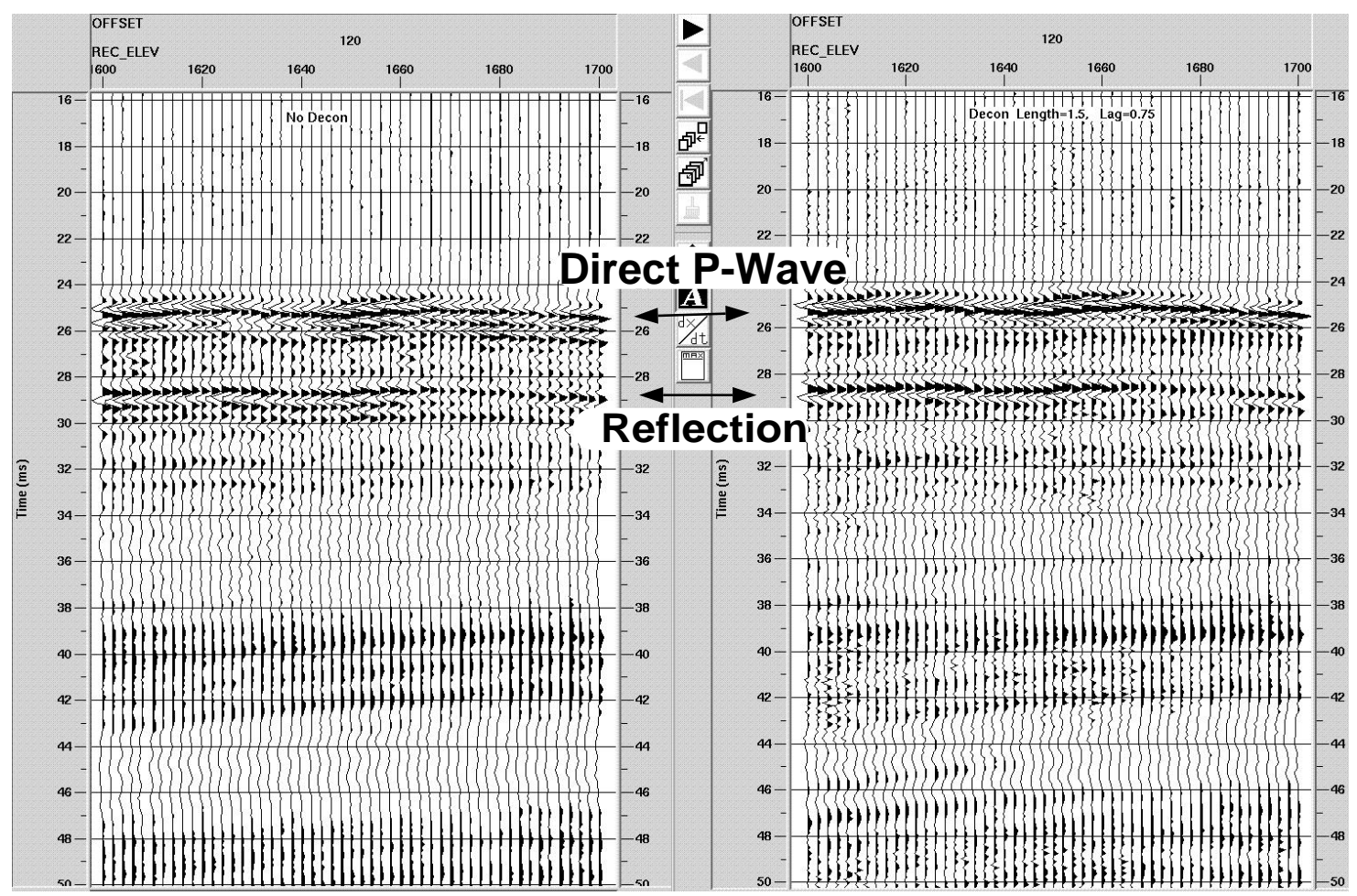

FIG. 6. Comparison of common offset gather (offset $=120 \mathrm{ft}$ ) before (left) and after (right) predictive deconvolution for source depths 1600 to $1700 \mathrm{ft}$. The deconvolution had an operator length of $1.5 \mathrm{~ms}$ and a prediction length of $0.75 \mathrm{~ms}$ with $0.1 \%$ noise added. 


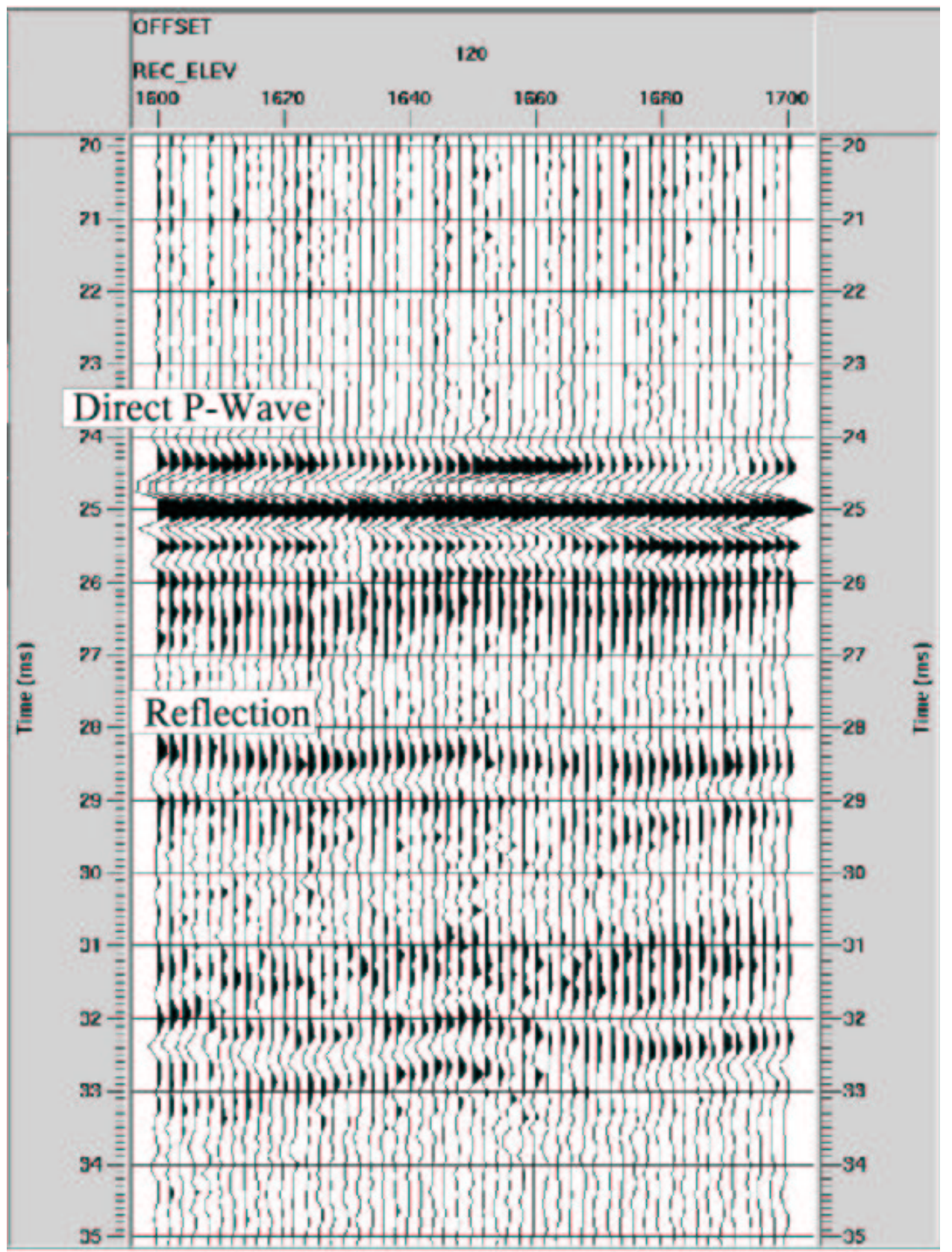

FIG. 7. Same data as Figure 6 with amplitudes normalized to individual trace maximum and time shifted to align the direct arrival at $25 \mathrm{~ms}$. 


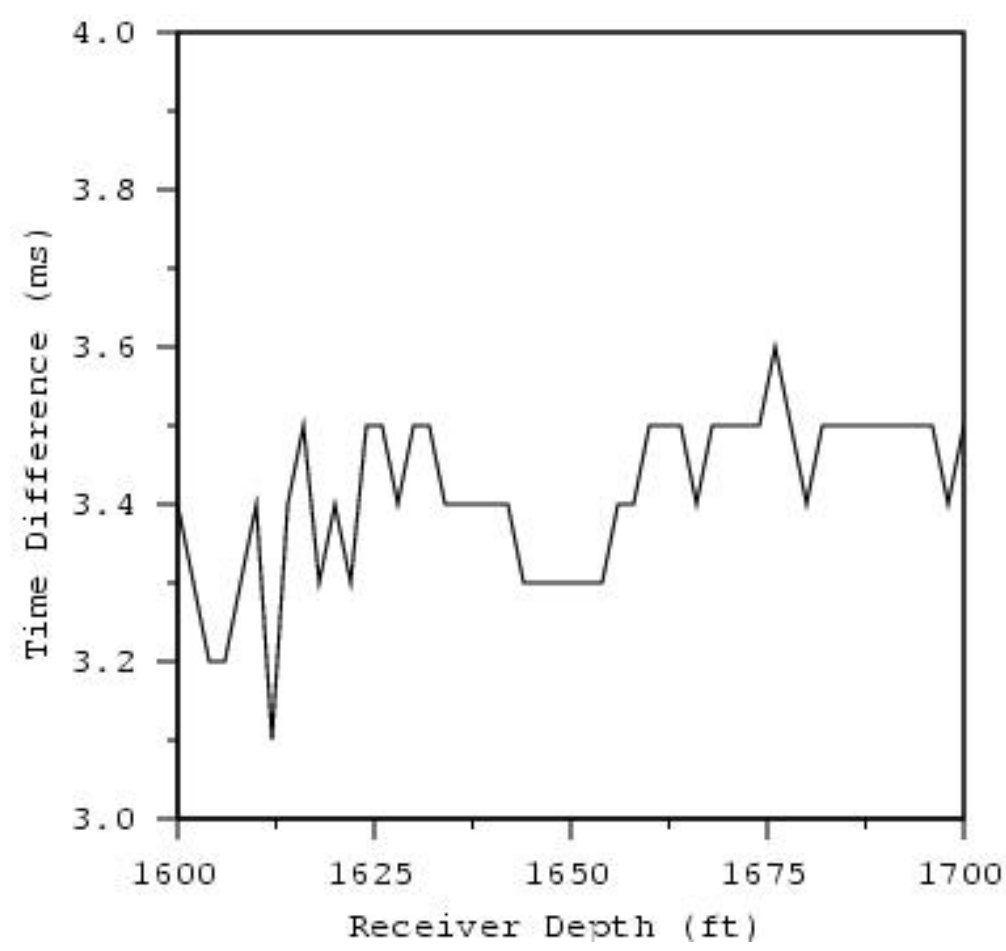

FIG. 8. Travel time difference between the direct $\mathrm{P}$-wave arrival and the interpreted reflection event for the data in Figure 7. 


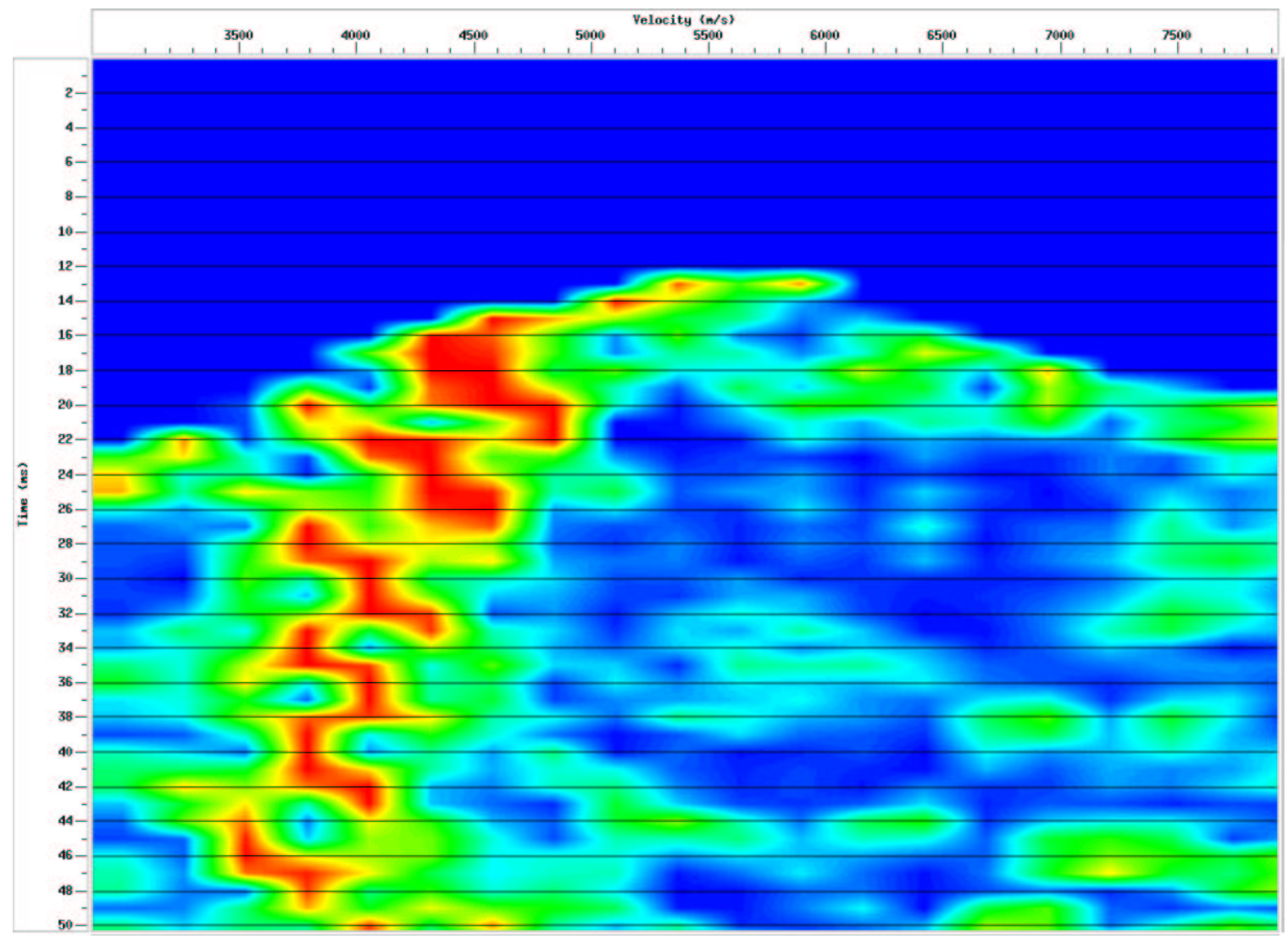

FIG. 9. Velocity semblance for $\mathrm{cmp} \#$ 645. Higher semblance is red (meaning larger amplitude within a time window after stacking). The small red bullseye at 12-14 ms and $5500 \mathrm{ft} / \mathrm{s}$ represents the energy associated with the interpreted hydrofracture reflection. The low velocity, high semblance energy is interpreted as borehole tube waves. 


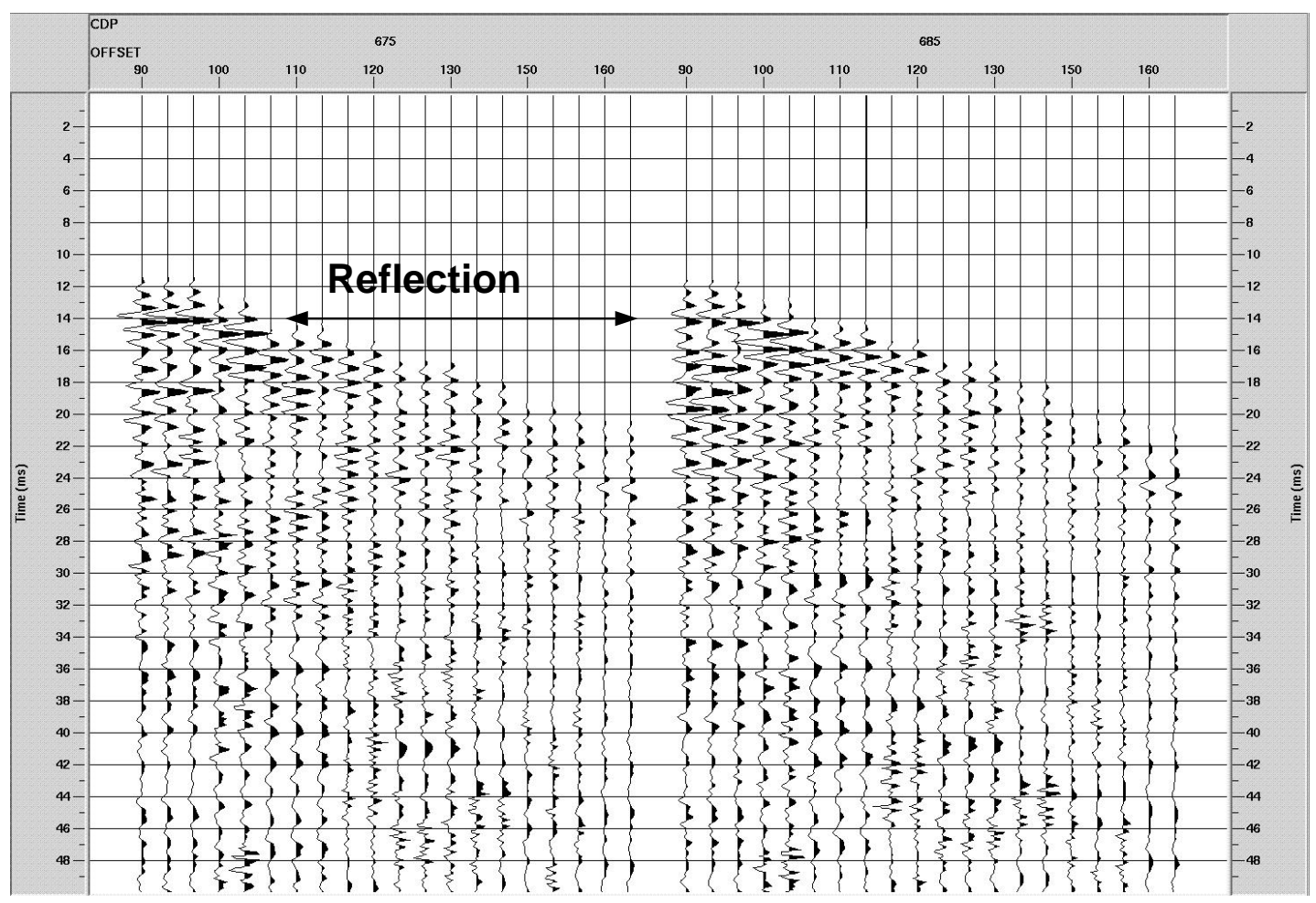

FIG. 10. NMO corrected CMP gather. Data are plotted at true relative amplitude after applying spherical divergence correction. 


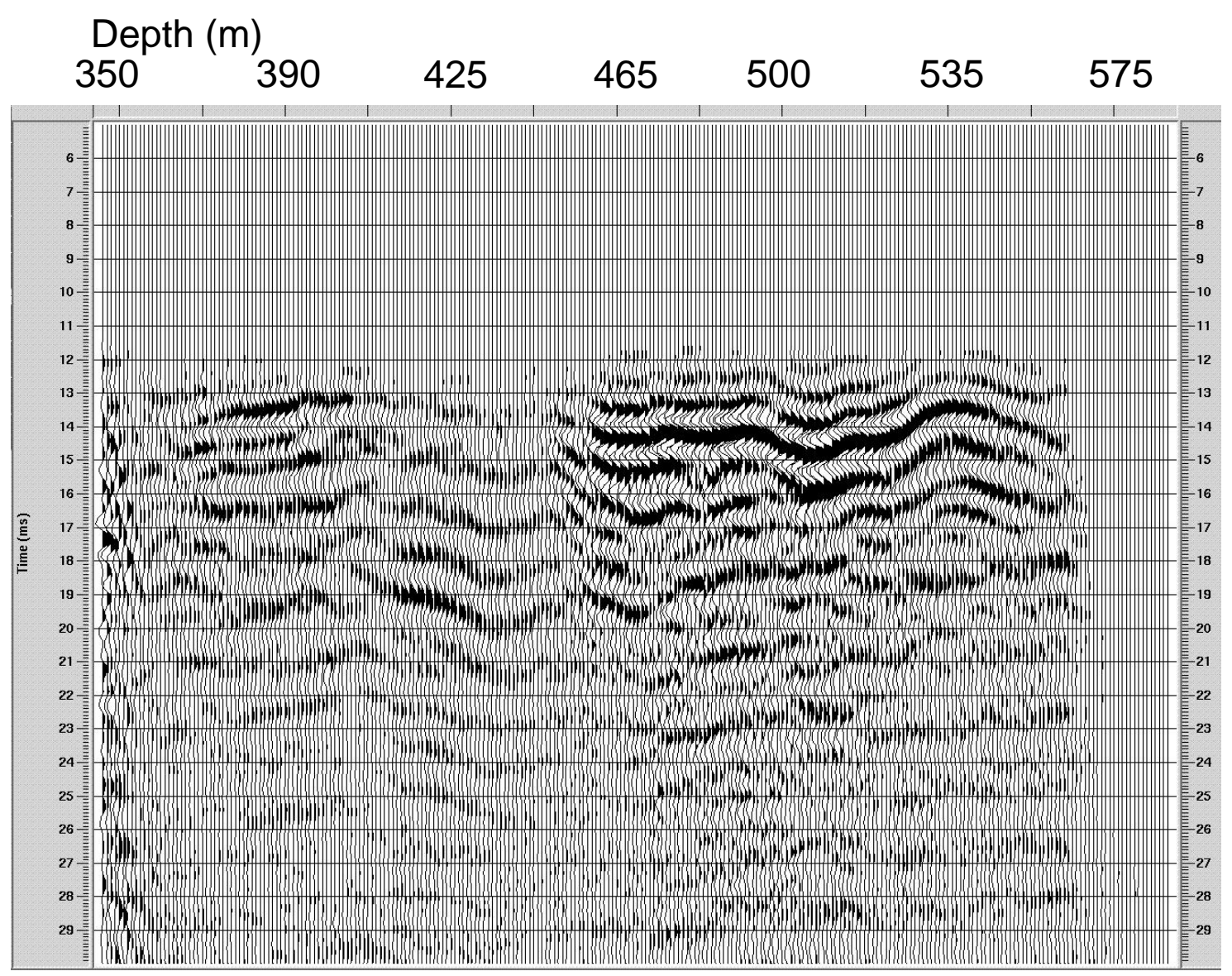

FIG. 11. Single well stacked CMP time section. 


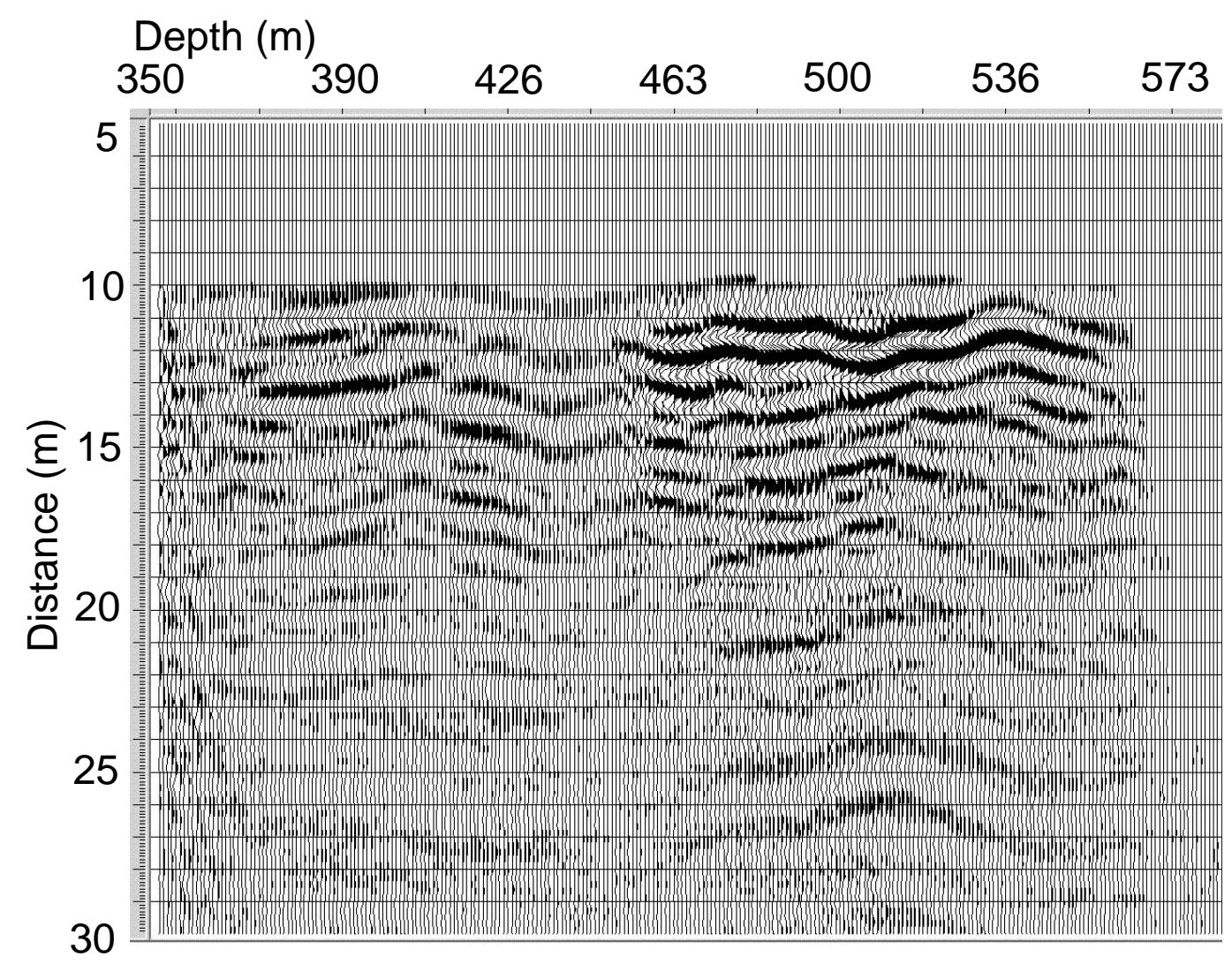

FIG. 12. Migrated single well CMP section. Distance in this section is radial (essentially horizontal) from the borehole, while depth is vertical along the borehole. 